Pak. j. sci. ind. res. Ser. A: phys. sci. 201255 (2) 112-116

\title{
Treatment of Domestic Wastewater Using Different Low Cost Materials
}

\author{
Muhammad Tahir Butt*, Naz Imtiaz and Tahira Shafiq \\ Centre for Environmental Protection Studies, PCSIR Laboratories Complex, \\ Ferozepur Road, Lahore - 54600, Pakistan \\ (received July 8, 2010; revised November 11, 2011; accepted November 18, 2011)
}

\begin{abstract}
Ash of burnt natural coal and low grade activated carbon was used for the reduction of chemical oxygen demand (COD) from sewage wastewater. To carry out this study a batch system was used for contact time, adsorption doze and $\mathrm{pH}$. The comparative study of ash (burnt natural coal) and low grade activated carbon shows that the absorption capacity of ash of burnt natural coal is lower than that of the low grade activated carbon, but its low commercial value makes it preferable as compared to the low grade activated carbon for the treatment of sewage for reduction of COD. The results show $69.34 \%$ and $97.39 \%$ removal of COD by ash and low grade activated carbon, respectively. Similar trend has been observed for treatment time, adsorbent dose and $\mathrm{pH}$ of solution. Ash shows quite effective adsorption capacity for COD reduction of the domestic wastewater, though its capacity is lower than that of commercial grade activated carbon. The low material cost makes ash an attractive option for the treatment of domestic wastewater.
\end{abstract}

Keywords: sewage wastewater, treatment, ash, activated carbon

\section{Introduction}

About $90 \%$ of the available water is used for irrigation purposes and $10 \%$ for municipal and industrial use. Per head consumption of water is about $250 \mathrm{~L}$, daily. Sewage is generated at the rate of $75 \%$ of water quantity consumed (Mumtaz, 2006). About one tenth of total sewage is treated in Karachi and remaining quantity is allowed to flow untreated into the Arabian Sea. Lahore does not have municipal sewage treatment plant. Small scale treatment plants have been installed in few houses, housing societies and institutions for the reuse of treated wastewater (Mumtaz, 2006). The principal objective of sewage treatment is to allow municipal and industrial effluents to be disposed of without danger to public health or to the environment.

Pollution of water by organic and inorganic chemicals is of serious environmental concern. Domestic wastewater differs in characteristics from the industrial wastewater. In domestic wastewater the organic load is mainly due to the processes like food processing, washing of floors, clothes, utensils, animals, bathing and sewage. The main components of domestic wastewater are proteins, carbohydrates, detergents, acids and many other dissolved organic compounds (Vijender et al., 2004; Ali and Deo, 1992). The organic content of wastewater is traditionally measured individually

*Author for correspondence; E-mail: pcsir322@gmail.com using lumped parameters such as biochemical oxygen demand (BOD), chemical oxygen demand (COD) and total organic carbon (TOC) (Pesscod and Arar, 1988).

A number of conventional treatment technologies have been considered for treatment of wastewater contaminated with organic substances. Among them, adsorption process is found to be of considerable interest during recent years. Commercial activated carbon is regarded as the most effective material for controlling the organic load. However, due to its high cost and about $10-15 \%$ loss during regeneration, unconventional adsorbents like fly ash, peat, lignite, bagass, pith and wood have also been widely investigated for the removal of organic materials (Ali and Deo, 1992) with varying degree of success.

Thus the removal of organic material by adsorption onto low cost waste material has recently become the subject of considerable interest. This approach offers a potentially simple and economical solution for effluent discharges. Ash is available in huge quantity having no commercial value. It can be used successfully to minimize load in domestic wastewater and the treated domestic wastewater containing acceptable amount of pollutant can be discharged into the receiving water bodies. Several investigators (Ali and Deo, 1992; Liskowitz et al., 1980) explored the use of fly ash as an adsorbent for the treatment of wastewater to remove 
a variety of organic compounds and colour. Investigations have also been made for the removal of copper from wastewater by using fly ash (used fly ash for the removal of chrome dye from aqueous solutions) and found that the mixture of fly ash and coal 1:1 have good adsorption of organic compounds from aqueous solutions. It was reported that the carbon content of fly ash plays a significant role during the adsorption of organic compounds by fly ash (Eye and Basu, 1970). The adsorption capacity increases with the increasing carbon content of fly ash. Other investigators observed an identical trend (Eye and Basu, 1970). However, a review of the literature showed that very little investigation has been conducted to find out the suitability of ash for the removal of COD from the domestic wastewater.

A number of treatment technologies have been considered for treatment of wastewater polluted with organic material. Adsorption is the most suitable method during recent research; scientists working in this field have found that low grade activated carbon is suitable to control the organic material in wastewater. Due to its cost and loss during the regeneration, unconventional adsorbents such as peat, bagass, wood, saw dust etc have attracted the scientists to use the adsorption materials for the removal of organic load from wastewater (Mumtaz, 2006, Vijender et al., 2004; Ali and Deo, 1992). This provides the commercial and economical solution of this problem for wastewater disposal according to the National Environmental Quality Standards (NEQS, 2000). When wastewaters are treated with a view to producing effluents for irrigation, the most appropriate method will be that which meets the recommended quality criteria specified for the intended use at low cost and with minimal operational and maintenance requirements and conventional treatment processes, involving primary, secondary and tertiary treatments. Although they produce good quality effluents, may not be economical or practical in many local situations. Hence, alternate treatment methods which are economical, efficient and reliable are needed in treating wastewaters for irrigation purposes (Banerjee et al., 1995; Gupta et al., 1990).

Ash is a residue that results from the combustion of natural coal. One of the main advantages of COD removal by using ash over the other chemical treatment methods is that, it is available in abundance and thus makes it a strong choice in the investigation of COD removing economically. The other advantage is that it could easily be solidified after the pollutants are absorbed because it contains different types of particles. In the present study domestic wastewater was analyzed for its major pollutants. The wastewater was treated with selected cheap adsorbents such as ash as an alternative medium to activated carbon to study the effects of treatment time, adsorbent dose, and $\mathrm{pH}$ on percentage reduction of COD.

\section{Materials and Methods}

Wastewater samples were collected from the E \& F type colonies of PCSIR Laboratories Complex, Lahore. The $\mathrm{pH}$ and electrical conductivity (EC) of the samples were measured on site and other parameters were analyzed in the laboratory according to standard methods ( Mumtaz, 2006). Five samples were taken at $30 \mathrm{~min}$ interval and stored at temperature below $20{ }^{\circ} \mathrm{C}$ to avoid any change in the physico-chemical characteristics. After screening, the sample with maximum contents of each pollutant was retained for further investigation. The maximum permissible temperature for the discharge of municipal liquid effluents is $40{ }^{\circ} \mathrm{C}$. The COD of the samples were estimated before and after adsorption giving different treatments. The ash was derived out of the burnt natural coal. The sample was washed with distilled water to remove surface dust and was dried at $105^{\circ} \mathrm{C}$. It was stored in an airtight plastic container.

This study was carried out using the $100 \mathrm{~mL}$ sewage water with initial COD having $1080 \mathrm{ppm}$ concentration.

Adsorption studies. All the experiments were carried out under controlled conditions in batch process. The batch experiments were run in different glass beakers of $500 \mathrm{~mL}$ capacity using average stirrer speed of $500 \mathrm{rpm}$. Prior to each experiment, a predetermined amount of adsorbent was added to each beaker. The stirring was kept constant for each run throughout the experiment ensuring equal mixing. The desired $\mathrm{pH}$ was maintained using dilute $\mathrm{NaOH} / \mathrm{H}_{2} \mathrm{SO}_{4}$ solutions. Each beaker was filled with a known volume of sample having desired $\mathrm{pH}$. The sample was stirred for predetermined time interval and filtered through Whattman No. 41 filter paper and then analyzed for the residual COD concentration (Mary and Franson, 2005; 1998).

Experimental conditions. These studies were conducted by stirring $300 \mathrm{~mL}$ sample with initial COD concentration 1080 ppm. Known amount of ash was added as 
an adsorbent and then stirred for different time periods (30-300 $\mathrm{min})$. After the predetermined time intervals, the samples were withdrawn, filtered and evaluated for the residual COD concentration. A known volume of the sample was treated with different doses of ash, 2.0-7.0 g/100 mL. The samples were stirred for specific time, filtered and then analyzed for the residual COD concentration (EEAA, 2002; NEQS, 2000).

\section{Results and Discussion}

Table 1, shows physico-chemical analysis of domestic wastewater which is heavily polluted with the organic load and suspended particles. Organic load is measured in terms of COD and BOD values. The COD concentration is much higher than the permissible limits.

Figure 1, represents the percentage removal of COD for different contact times both by the ash and commercial activated carbon. The results obtained show that COD removal has been achieved to the extent of

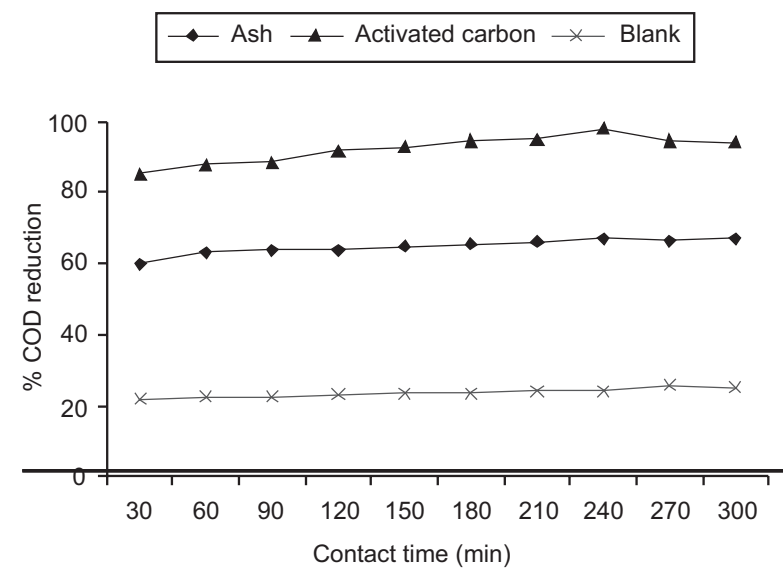

Fig. 1. Effect of contact time on \% COD reduction by ash, activated carbon and blank. more than $97.39 \%$ by activated carbon and $69.39 \%$ by ash at a maximum time period of $250 \mathrm{~min}$. The results show that the trend of percentage COD reduction with ash was comparable to that of commercial activated carbon. The smooth and independent nature of curve indicates formation of curve on adsorbent on the outer surface of the adsorbent (Gupta et al., 1990). A blank sample without adsorbents was also used which showed $25 \%$ removal of COD.

Figure 2 shows the effect of various doses of ash and activated carbon on the percentage COD reduction by ash and also compared its trend with that of commercial activated carbon. It was observed that the maximum percentage of COD removed was $79.39 \%$ by ash dose of $60 \mathrm{~g} / \mathrm{L}$ and $97.39 \%$ by activated carbon dose of $50 \mathrm{~g} / \mathrm{L}$. After that the equilibrium was set up by further addition of adsorbent dose. Ash shows fairly the same trend to that of commercial activated carbon. The trend of dose effect on percentage COD reduction both by

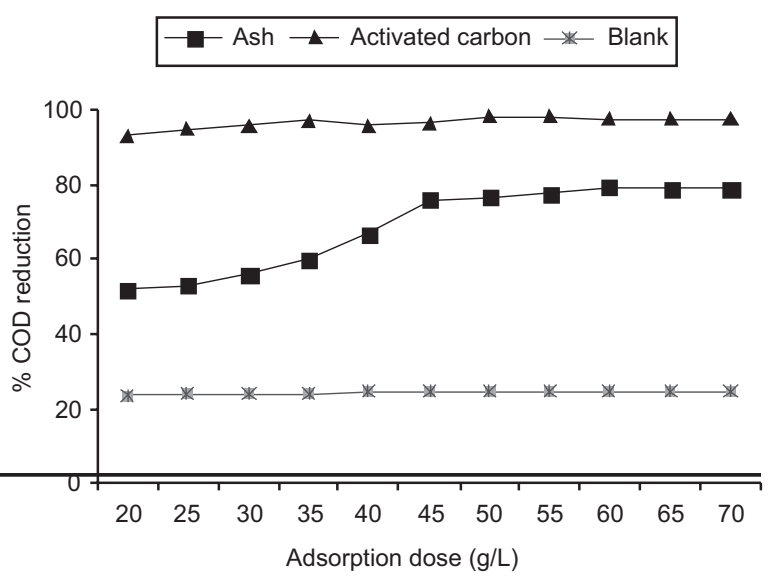

Fig. 2. Effect of contact dose on $\%$ COD reduction by ash, activated carbon and blank.

Table 1. Physico-chemical analysis of domestic wastewater

\begin{tabular}{llll}
\hline \hline S. No. & Parameters & Waste water sample analysis & $\begin{array}{l}\text { Maximum permissible limit } \\
\text { NEQS }(2000)\end{array}$ \\
\hline 1. & $\mathrm{pH}$ & 8.52 & $6-10$ \\
2. & Electrical conductance & $1766 \mu \mathrm{s} / \mathrm{cm}$ & Not applicable \\
3. & Temperature $\left({ }^{\circ} \mathrm{C}\right)$ & 20.5 & 40 \\
4. & Total solids $(\mathrm{mg} / \mathrm{L})$ & 1031.0 & 3650 \\
5. & Total suspended solids $(\mathrm{mg} / \mathrm{L})$ & 341.0 & 150 \\
6. & Total dissolved solids $(\mathrm{mg} / \mathrm{L})$ & 790.0 & 3500 \\
7. & Chemical oxygen demand (COD) $(\mathrm{mg} / \mathrm{L})$ & 1080.0 & 150 \\
8. & Biochemical oxygen demand (BOD) $(\mathrm{mg} / \mathrm{L})$ & 386.0 & 80 \\
\hline \hline
\end{tabular}


ash and activated carbon are also presented. The results in Fig. 2 show the tremendous increase in percentage COD removal with the increment of adsorbent dose, owing to the increase in the number of sites (APEC, 2005; Nelson and Guarino, 1969). At lower doses, the significant small adsorption is possibly due to the saturation of active sites with adsorbent molecules. A blank experiment was also carried out and their results are presented in Fig. 2.

Figure 3 indicates the effect of $\mathrm{pH}$ on COD percentage reduction by ash and commercial activated carbon. The runs were taken at the constant initial COD concentration, adsorbent dose and the contact time. The results indicate that at all $\mathrm{pH}$ values below 4.0 the ash has consistently higher adsorption capacity for COD. There is more than $80 \%$ drop in COD percentage by ash. At high $\mathrm{pH}$ the capacity of adsorbent reduces. The better adsorption of organic chemicals COD by ash at low $\mathrm{pH}$ may be attributed to the large numbers of $\mathrm{H}^{+}$ions present, which in turn neutralize the negatively charged adsorbent surface, thereby reducing hinderance to the diffusions of organics in the wastewater. On the contrary low adsorptions i.e. low COD removal observed at $\mathrm{pH}$ values higher than 4 are attributed to the presence of excessive $\mathrm{OH}^{-}$ions in the system, causing increased hinderance to diffusion of organic ions in the system. Oxides of aluminum, calcium, silicon, iron etc are abundant in fly ash (Banerjee et al., 1995; Liskowitz et al., 1980). The hydroxylate surfaces of these oxides in aqueous medium undergo dissociation resulting in increased number of sites for the adsorption of COD. Similar observations pertaining to colour, organic and chromium removal have been reported in the literature

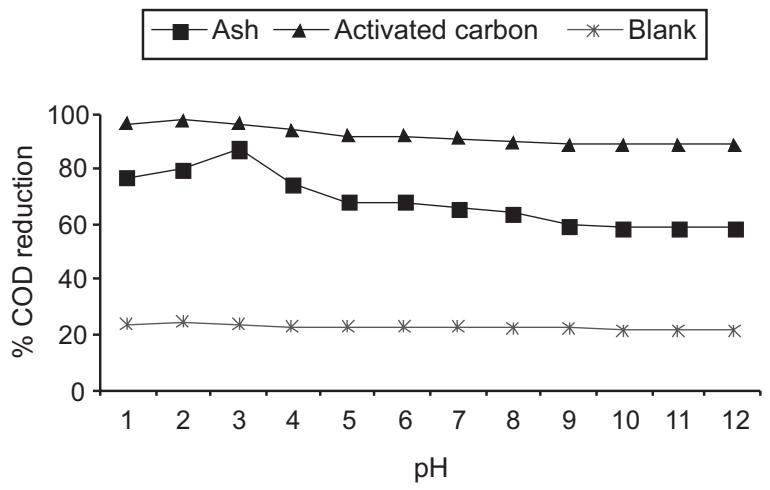

Fig. 3. Effect of $\mathrm{pH}$ on $\% \mathrm{COD}$ reduction by ash, activated carbon and blank.
(Eye and Basu, 1970). The blank experiment was also carried out and results are shown in Fig. 3.

\section{Conclusion}

The present study demonstrated that the treatment of domestic wastewater to reduce the organic load can be done by using ash. It is observed that the COD can be reduced up to the extent of $87.89 \%$ by using ash at $\mathrm{pH} 3$. Trend of \% COD removal by ash is fairly comparable to that of commercial activated carbon. The results also indicate that the ash is physically viable and economically useful for treatment of domestic waste water.

\section{References}

Ali, M., Deo, N. 1992. Effect of pH on adsorption process of chromium (VI) with a new low cost adsorbent with a new low cost adsorbent. Indian Journal of Environmental Pollution, 12: 202-209.

APEC, 2005. Common water quality problems and their methods of treatment.http://www.freedrinking water.com/water-education/water-filters-rocontaminantremoval.htm.

Banerjee, K., Cheremisinoff, P.N., Cheng, S.L. 1995. Sorption of organic contaminants by fly ash in a single solute system. Environment of Science \& Technology, 29: 2243-2251.

EEAA, 2002. Introduction to Industrial Wastewater Treatment Plants, Inspection Procedures Manual. pp. 4-13, Egyptian Environmental Affairs Agency, Egypt.

Eye, D.J., Basu, T.K. 1970. The use of fly ash in wastewater treatment and sludge conditioning. Journal of the Water Pollution Control Federation, 42: 125-135.

Gupta, G.S., Prasad, G., Singh, V.N. 1990. Removal of chrome dye from aqeous solutions by mixed adsorbents by fly ash and coal. Water Research, 2: 24-45.

Liskowitz, J.W., Cham, P.C., Trattner, R., Sheih, M. 1980. Leachate treatment utilizing fly ash clay mixture. In: Proceedings of National Conference on Hazardous and Toxic Waste Management, New Jersey, USA, 2: 515-544.

Mary, A.H.F. (ed.). 2005. Standard Methods for the Examination of Water and Wastewater. pp. 5-16, $21^{\text {st }}$ edition, American Public Health Association, USA.

Mary, A.H.F. (ed.). 1998. Standard Methods for the 
Examination of Water and Wastewater. pp. 5-16, $20^{\text {th }}$ edition, American Public Health Association, USA.

Mumtaz, H. 2006. Wastewater management in Pakistan challenges and prospects. The Environment Monitor, 6: $19-22$.

Nelson, M., Guarino, F. 1969. The use of fly ash in municipal waste treatment. Journal of the Water Pollution Control Federation, 41: 1905-1911.

NEQS, 2000. National Environmental Quality Standards for Municipal Wastewater and Liquid Industrial
Effluents. Gazette Notification. August, 2000. Ministry of Environment, Local Government and Rural Development, Islamabad, Pakistan.

Pesscod, M.B., Arar, A. 1988. Treatment and Use of Sewage Effluent for Irrigations Pub., 182 pp. By Food and Agriculture of United Nations by Butterworth, London, UK.

Vijender, S., Dahiya, R.P., Gadgil, K. 2004. Fly Ash Based Low Cost Method for COD Removal from Domestic Wastewater, pp. 1-6, Geospatial Resource Portal GIS Develop Pvt. Ltd. Noida, India. 